\title{
Os desafios do MST e da educação na atualidade brasileira
}

\author{
Célia Regina Vendramini*
}

\begin{abstract}
Resumo
O artigo propóe uma reflexão sobre a atualidade das lutas do Movimento dos Trabalhadores Rurais Sem Terra na realidade brasileira, num contexto de crescente urbanização. A partir de pesquisas realizadas nos últimos anos sobre a experiência educacional do MST, apresenta-se o contexto histórico de emergência do Movimento, com base na articulação entre os aspectos econômicos, políticos e educacionais; a reação organizada dos trabalhadores sem-terra, seus objetivos e formas de luta e, especificamente, a importância atribuída à educação; por fim, os desafios atuais do MST e dos seus propósitos educacionais. O movimento analisado neste artigo, nos leva a refletir sobre alguns desafios teóricos e práticos na atualidade, referentes ao campo e sua articulação com a cidade, à ruptura com a histórica concentração da propriedade da terra e da riqueza no Brasil, às lutas organizadas dos trabalhadores e suas experiências de cooperação, autogestão e educação/escolarização de sua base. A educação é compreendida no seu contexto histórico, social, econômico e político, sendo fruto das relaçóes sociais.
\end{abstract}

Palavras-chave: Movimento dos Sem-Terra. Movimentos Sociais e Educação. Trabalho e Educação.

\footnotetext{
* Doutora em Educação pela Universidade Federal de São Carlos (UFSCar). Professora associada IV da Universidade Federal de Santa Catarina (UFSC).
} 
No início do século XXI, num mundo urbanizado, em que a maioria da população vive nas cidades, qual a motivação para refletir sobre um movimento social que luta pela terra e pela reforma agrária no Brasil? O sentido para o estudo do Movimento dos Trabalhadores Rurais Sem Terra, conhecido como MST, está no seu caráter universal. Apesar de sua especificidade, o MST náo deixa de refletir a generalidade dos confrontos históricos e os problemas que desafiam a criatividade dos trabalhadores em geral, há pelo menos dois séculos.

O MST é a expressão do mundo em que vivemos, do fardo que carregamos e do desafio que temos pela frente, numa referência à obra de István Mészáros (2007), O desafio e o fardo do tempo histórico. O fardo se expressa nos mais de 500 anos de exploração, num contexto de extrema desigualdade social, num campo ocupado pelo agronegócio (da soja, da canade-açúcar, do pinus e eucalipto) e numa cidade em que reina o desemprego, a violência e a indiferença.

Como a realidade é dialética, há fardo, mas também há desafio. O MST desafia a ordem, a propriedade e o capital. Numa alusão a José Saramago quando afirmou: "Eu escrevo para os desassossegados", vemos que o MST é o desassossego! Ele nos desafia a pensar e a agir na direção de um novo equilíbrio da vida social, numa nova forma de apropriação do espaço em que vivemos e em novos processos educacionais.

Visando compreender a complexidade do MST e dos seus propósitos educacionais, bem como da realidade em que ele emerge, buscamos neste artigo contextualizar o Movimento com base na dialética passado, presente e futuro, assim como analisar as contradiçôes que ele expressa ao emergir nas velhas relaçôes sociais e perspectivar novas relaçóes. Levamos o leitor a observar os elos existentes entre a educação e as condiçóes econômicas, sociais e políticas do campo brasileiro que fizeram emergir o Movimento dos Sem Terra.

Com base em pesquisas desenvolvidas pela autora nos últimos anos sobre a experiência educacional do MST, apresentamos, neste artigo, o contexto histórico de emergência do Movimento, com base na articulação entre os aspectos econômicos, políticos e educacionais; a reação organizada dos trabalhadores sem-terra, seus objetivos e formas de luta e, especificamente, a importância atribuída à educação; e, por fim, os desafios atuais do MST e dos seus propósitos educacionais. 


\section{O contexto de emergência do Movimento dos Trabalhadores Rurais Sem Terra}

O MST há 30 anos está à frente da luta pela terra no Brasil, por meio de ocupações de terra, de acampamentos e da constituição de assentamentos. Está organizado em 24 Estados, nas cinco regióes brasileiras e já conquistou a terra para 350 mil famílias, por meio da luta e da organizaçáo dos trabalhadores.

Existem 1,9 mil associaçóes e 100 cooperativas nos assentamentos que trabalham de forma coletiva ou semi-coletiva, muitas delas produzindo sem agrotóxicos; 96 agroindústrias; mais de duas mil escolas públicas em acampamentos e assentamentos que atendem a 160 mil crianças e adolescentes, na educação básica e no ensino médio; alfabetização de 50 mil adultos nos últimos anos; mais de 100 cursos de graduaçáo em parceria com universidades em todo o país, além de cursos de especialização ${ }^{1}$.

O MST é fruto da histórica concentração da terra no Brasil ${ }^{2}$ e, ao mesmo tempo, da fase mais avançada e moderna do capitalismo em âmbito mundial, expresso na atualidade por meio do chamado agronegócio. Emerge como expressão da desigualdade social no país, da expropriação e exploração dos trabalhadores, bem como do avanço do desemprego e das formas de intensificação/precarização do trabalho.

A existência do MST encontra explicação na constituição social, econômica e política do Brasil. Um país em que predominou em termos econômicos o modelo agrário-exportador, com produção monocultora voltada para a exportação, como a cana-de-açúcar, o algodão, o café, e hoje a soja, a laranja ou os agrocombustíveis. Um país colônia no contexto de um processo mundial de expansão e acumulação mercantil de capital, segundo Caio Prado Júnior (1942), é hoje um país exportador de capitais.

$\mathrm{Na}$ segunda metade do século XIX, alguns fatos ocasionam grandes mudanças: a Lei de Terras de 1850 que tornou a terra uma mercadoria que pode ser vendida e comprada, nesse período quase toda a terra já estava dividida em latifúndios, portanto, a Lei solidificou a grande propriedade; o fim do tráfico de escravos em 1850 e a Aboliçáo da escravatura em 1889; a imigraçáo de colonos estrangeiros a partir de 1870, visando trazer para o Brasil trabalhadores europeus que viriam substituir os ex-escravos, os quais sem opção vão constituir as favelas brasileiras. Os imigrantes trazem para o Brasil a experiência do trabalho assalariado já instalado na Europa, num contexto em que o capitalismo se 
institui criando uma grande força de trabalho de reserva. Estes trabalhadores também trazem para nosso país a experiência anarco-sindicalista, constituindo os primeiros sindicatos de trabalhadores.

Vamos observar que a constituição do MST no Sul do Brasil entrelaçase com o destino de muitos imigrantes oriundos do processo de emprego e desemprego europeu. Com a mudança de milhóes de pessoas desloca-se o eixo de uma grande crise que atravessava países europeus no século XIX. Como resultado do deslocamento populacional, cria-se uma poderosa sobrevida à acumulação capitalista.

No predomínio do modelo agrário-exportador, em que a maioria da população vive na zona rural, numa produção com base em fatores arcaicos, não se cria a necessidade de educação da população e nem mesmo de desenvolvimento científico e tecnológico. A educação não é chamada a responder desafios da situação política e econômica. O ensino é desinteressado, deve dar cultura geral a uns poucos privilegiados, sem preocupação em qualificar para o trabalho. É uma educação de elite. A instrução fora um privilégio aristocrático na antiga ordem social escravocrata, assim se manteve, na essência, por mais meio século de experiências republicanas, segundo Fernandes (1966).

A partir de 1930 são criadas condiçóes externas e internas que levam à necessidade de mudança do modelo econômico até então predominante. Com a crise mundial de 1929, o Brasil que sempre se estruturou por meio da produção agrícola para a exportação, é levado a buscar alternativas internas de produção. Desencadeia-se assim um processo de industrialização chamado dependente, pois depende de know-how e equipamentos estrangeiros para a produção industrial. É um modelo de substituição de importaçôes, em que a importação de bens de consumo é substituída pela produção industrial moderna. Nesse processo, há uma clara transferência de renda do setor tradicional (área agrícola) para o moderno (industrial). Segundo Romanelli (2006), enquanto a modernização econômica implicar intensificação da importação tecnológica, a escola não será chamada a desempenhar papel de relevo, a não ser num dos setores básicos da expansão econômica: treinamento e qualificação de força de trabalho.

A economia agroexportadora foi utilizada como acumulação primitiva de capital que financiou a industrializaçáo, cujas máquinas e equipamentos advinham dos países do capitalismo central. A passagem da economia agrícola à industrial ocorre através de um lento e constante reajustamento de interesses 
entre a classe burguesa em ascensão e os velhos setores oligárquicos, e de ambos com o capital internacional, que se processa impedindo a participação popular (FERNANDES, 2006). Nossa longa trajetória colonial, subdesenvolvida e dependente da metrópole, é perpetuada no contexto da república, já com uma nova configuração das classes no poder. Estas aceitam a posição secundária do Brasil na economia internacional, mas garantindo elevados ganhos para alguns setores desta classe. Dentre algumas das principais implicações deste padrão de economia subordinada, encontra-se a constituição de um frágil mercado interno e as desigualdades regionais e sociais.

Grande parte da população é deslocada para as cidades, formando uma massa de trabalhadores disponíveis ao capital. Entretanto, a trajetória brasileira não constitui dois Brasis, um moderno e outro atrasado, um rico e outro pobre, um que se desenvolve e outro que impede o desenvolvimento. Oliveira (2003), criticando esta abordagem dualista, aponta que no Brasil a moderna indústria se alimentou do atraso da economia de subsistência. "A agricultura atrasada financiava a agricultura moderna e a industrialização" (OLIVEIRA, 2003, p. 129), tanto baixando o custo da força de trabalho urbana quanto promovendo o excedente de mão de obra. Dessa forma, para o autor, "o subdesenvolvimento não era, exatamente, uma evolução truncada, mas a produção da dependência pela conjunção de lugar na divisão internacional do trabalho capitalista e a articulação dos interesses internos" (OLIVEIRA, 2003, p. 127). Assim, "o subdesenvolvimento viria a ser, portanto, a forma da exceção permanente do sistema capitalista na sua periferia" (OLIVEIRA, 2003, p. 131).

De acordo com Romanelli (2006), o sistema escolar refletiu as contradições entre os aspectos modernos assumidos pelo desenvolvimento e o arcaísmo de certas facçôes da elite dominante. No contexto pós-1930, novas exigências educativas emergem, com a intensificação do capitalismo industrial no Brasil. Cresce a demanda social de educação e a pressão pela expansão do ensino. Monteiro Lobato (1951), no conto Urupês, denuncia a figura do Jeca Tatu como a causa do precário e atrasado progresso brasileiro no campo. A escola, a extensão rural, a alfabetização de adultos, os programas educativos visavam superar a figura do Jeca Tatu, tratado como preguiçoso, ignorante e avesso ao progresso.

Os programas educacionais para o campo podem ser compreendidos dentro do que veio a se chamar "ruralismo pedagógico", como resposta ao êxodo rural, visando fixar o homem na terra, reforçando os seus valores, a partir da 
crítica ao urbanismo. Propóe uma educação que ruralize o rural. No contexto brasileiro, o movimento que predomina neste período em termos educativos é o Escolanovismo, apresentado no Manifesto dos Pioneiros da Escola Nova, em 1932, o qual defende escola para todos, laica e sob responsabilidade do Estado, visando por meio da educação a equalização de oportunidades e a ascensão social.

Nos anos 1960, observa-se uma intensificação do processo de modernização da economia brasileira, visando levar o Brasil à condição de país desenvolvido, por meio da internacionalizaçáo da economia, numa opção de inserção definitiva do país na esfera de controle do capital internacional.

No campo brasileiro, tal processo ficou conhecido como Revoluçáo Verde, a qual impôs um novo padrão produtivo, dependente de produtos químicos comercializados por empresas estrangeiras. Tal perspectiva de desenvolvimento do campo visa modernizar a agricultura brasileira no que se refere à sua inserção no mercado agrícola mundial, tanto em termos de produtividade quanto de consumo. Temos, entấo, uma mudança de matriz tecnológica e produtiva, com a dispensa de força de trabalho devido à mecanização, à utilização massiva de insumos industriais com a dependência dos produtores da indústria, dos financiamentos bancários e das grandes multinacionais exportadoras. Essa nova base produtiva reforçou a monocultura em grandes extensóes e as exportaçóes de novos produtos agrícolas como a soja e o milho. Mas também elevou muito a pobreza no campo, atualizou a concentraçáo da terra e promoveu o êxodo rural. É a chamada modernização conservadora da agricultura (mudança técnica sem mudança na estrutura agrária), expressão cunhada por José Graziano da Silva (1982).

De acordo com Romanelli (2006), a modernização do sistema educacional foi a resposta à crise educacional dos anos 1950 e 1960, com a função de melhor integrar o Brasil na expansão do capitalismo ocidental e mantê-lo em sua posição periférica. A educação apresenta-se como fator na produção de recursos humanos para o desenvolvimento desejado, com a "ajuda" internacional, no âmbito dos acordos do Ministério da Educação e United States Agency for International Development (MEC-USAID). É nesse contexto, que se apresenta a educação tecnicista, visando eficiência, produtividade, controle e repressão, no contexto de ditadura militar.

O ensino técnico assume importância no processo de modernização da base técnica da agricultura brasileira. Além disso, visa impedir o crescente êxodo rural. O sistema Escola-Fazenda, em regime de internato, foi introduzido 
em 1966, no âmbito do acordo MEC-USAID acima referido. Visa conciliar, segundo Sobral (2005), educação, trabalho e produção, com objetivo de otimizar os resultados da escola e torná-la eficiente e funcional. Na década de 1970, o Banco Mundial financiou vários projetos junto ao MEC, entre eles a melhoria e a expansão do ensino técnico de $2^{\circ}$ grau, industrial e agrícola, com base no modelo escola-fazenda.

$\mathrm{Na}$ atualidade, tal modelo é levado às últimas consequências, por meio do chamado agronegócio, expressão do atual estágio do capitalismo financeiro e oligopolizado. A política econômica externa, segundo Delgado (2003), incorpora o setor agrícola na solução do endividamento externo, o que reforça a estratégia de concentração e especulação fundiária no mercado de terras. O agronegócio é a resposta a esta estratégia, na medida em que associa o capital agroindustrial com a grande propriedade fundiária, perseguindo o lucro e a renda da terra, sob patrocínio de políticas de Estado, além de desmobilizar as forças sociais aliadas à reforma agrária.

$\mathrm{Na}$ análise de Delgado (2003), a expansão do produto da agropecuária, sob comando do agronegócio, se faz sob três restrições essenciais: restrição da demanda interna de bens e serviços; limitação das oportunidades de emprego; e manutenção de amplas áreas de terras improdutivas. Conclui que sem mexer nestas restriçõos, não há possibilidade de crescimento econômico contínuo, com mudança na estrutura agrária e geração de emprego.

Segundo o mesmo autor, a magnitude da questão agrária hoje está na disponibilidade de terra e na demanda por terra. A situação agrária brasileira descarta trabalhadores e pequenos produtores dos mercados agrícolas e, ao mesmo tempo, permite um grande estoque de terra ociosa apropriada pelo latifúndio.

Delgado (2009) apresenta vários indicadores afetados pela atual expansão agrícola acelerada - desmatamento florestal, aumento da grilagem de terras, perda de eficácia do manejo e conservação dos recursos hídricos, perda da biodiversidade em razão da expansão da monocultura. Indicadores estes acentuados pelo aumento de doenças laborais e pela violência que permeia as relaçôes semiclandestinas de trabalho volante, marcas do perverso processo de expansão agrícola.

$\mathrm{Na}$ atualidade, a educação tecnológica assume a responsabilidade pelo desenvolvimento econômico do país, a estilo da Teoria do Capital Humano, 
com o ideário de formação para qualidade total, formação abstrata, qualificação flexível e polivalente, como solução para o desemprego. Mantém-se, assim, a crença na educação para o desenvolvimento econômico produtivo.

Observa-se a fragmentação e o empobrecimento da formação profissional, com cursos práticos de curta duração, aliados ao modelo de certificação de competências, noção que substitui a qualificação, num contexto de diminuiçẫo dos recursos públicos para com a educação, em que não interessa a geração de tecnologia. As escolas agrotécnicas, segundo Sobral (2005), não tem como objetivo a formação de técnicos para atender o pequeno e médio produtor rural, mas para servir ao grande capital.

Nesse contexto, cabe ao indivíduo exercer sua capacidade de escolha visando a adquirir os meios que lhe permitam ser competitivo no mercado de trabalho. É a educação, conforme Saviani (2008), sinônimo de investimento em capital humano individual que habilita as pessoas para a competição pelos empregos disponíveis.

\section{A reação organizada dos trabalhadores, o MST e a educação}

O MST é fruto do contexto histórico acima apresentado de forma sintética, mas também resulta das históricas resistências dos trabalhadores rurais, como as indígenas, os Quilombos, o Movimento do Contestado em Santa Catarina, de Canudos na Bahia, as Ligas Camponesas no Nordeste brasileiro, movimentos de posseiros, de pequenos agricultores, entre outros ${ }^{3}$. Mais especificamente, expressa o reascenso dos movimentos e sindicatos após os longos 21 anos de ditadura militar no Brasil, marcado particularmente pelas greves dos trabalhadores do ABC paulista no final da década de $1970 \mathrm{e}$ início da década de 1980. Tais lutas são um exemplo para a organização dos trabalhadores, entre elas a dos sem-terra.

Além disso, o Movimento é fruto, particularmente, de uma série de movimentos localizados e açóes de ocupação de terra no Sul do país. Define-se como um movimento social de "caráter popular, sindical e político". Desde sua fundação expressa três grandes objetivos: "a luta pela terra, por Reforma Agrária e por uma sociedade mais justa” (GORGEN; STÉDILE, 1993).

A principal forma de luta utilizada pelo Movimento são as ocupações de latifúndios e os acampamentos, cuja presença de centenas ou mesmo milhares de famílias exerce grande pressão por sua desapropriação. A ocupação e os acampamentos são açôes de grande radicalidade, pois questionam a propriedade 
privada da terra. O MST é um movimento social cuja originalidade e expressividade ancora-se em sua organização nacional (onde se destaca o grau de articulação interna, presença efetiva em todos os estados e homogeneidade nas formas de luta); a combatividade permanente (na ocupação do latifúndio até a organização dos assentamentos uma vez conquistada a terra); o protagonismo autotransformador (pondo amplas massas na condição de sujeitos em luta); suas práticas politizadoras e a radicalidade de sua luta que questiona o fundamento da ordem existente (VENDRAMINI, 2000).

O MST desafia os quadros teóricos de análise, pois dificilmente se enquadra num deles. Ele não se constitui num partido político, ainda que tenha uma estrutura organizacional nacional, regional e local parecida (VENDRAMINI, 1992). Também não é um movimento social como os que se constituíram a partir de 1968 , no que veio a ser denominado como "novos movimentos sociais", uma abordagem que pretende substituir os conceitos classistas e as análises em termos de processos históricos globais por noçôes que priorizam o caráter individual e específico de certos grupos organizados.

Ao contrário do que preconiza Alain Touraine (1999), um dos formuladores dessa noção, o MST é um movimento de classe, sua luta se desenvolve no terreno dos direitos sociais, apresenta reivindicação contra a ordem dominante, tem claramente uma direção política, seus objetivos de luta não são apenas imediatos, pontuais e parciais, mas visam a transformação social, ou seja, defendem um projeto histórico, de futuro.

Para completar o desajuste teórico, o MST é um movimento social que completa, em 2014, 30 anos, diferente de grande parte dos movimentos, os quais têm vida curta, visto que ao ter atendida sua reivindicação, geralmente pontual, não tem mais razão de existir.

Como um movimento da atualidade, o MST mostra-se capaz de unir a esfera política com a produtiva. Isto quer dizer que suas lutas massivas de enfrentamento no campo da política se articulam com a construção de experimentos, ou laboratórios sociais, no interior dos assentamentos como estratégia coletiva de produção material da vida. Constituindo-se, na designação de Harvey (2005), como "espaços de esperança".

Dos movimentos sociais organizados no Brasil, o que mais dedicou atenção à educação foi o movimento anarquista, segundo Vianna (2008), e hoje o MST chama a atenção pela sua preocupação com a questáo educacional 
e escolar, provavelmente por três particularidades: 1) ao engajar na sua luta toda a família, portanto, também crianças de todas as idades; 2) em função da educação para a população rural sempre ter ocupado lugar secundário e a margem no sistema educacional brasileiro; 3 ) porque os programas existentes para a educação rural eram modelos prontos, de cima para baixo, visando mais a moralização, a civilização, a higienização, do que propriamente a educação e o acesso aos conhecimentos. De acordo com Fernandes (1966), o ensino como privilégio social se reflete em dois setores vitais: no grau de diferenciação e organicidade do sistema nacional de educação, com desequilíbrio no desenvolvimento dos diferentes ramos de ensino, e na forma de distribuiçáo das escolas dos diferentes níveis pelo país. As oportunidades educacionais se concentram em certas regióes. No caso do meio rural, tradicionalmente, as oportunidades educacionais foram desproporcionalmente inferiores.

Como hipótese, acrescento um quarto aspecto, o qual diz respeito a uma aposta excessiva na educação como meio de formação de quadros e militantes para as fileiras do Movimento. Algo que herda da influência religiosa na sua constituiçáo, do movimento de educaçáo popular e das ideias de Paulo Freire centradas na conscientizaçấo como elemento central da libertação dos homens e, contraditoriamente, das ideias do ruralismo pedagógico que viam na educação a solução para conter o êxodo rural. Hoje, particularmente esta última, está presente em muitas análises da educação do campo permeadas de romantismo acerca do campo e da educação que lá se desenvolve.

O MST, desde a sua origem, inclui a escola como um campo de lutas. Os primeiros acampamentos já manifestavam preocupação e buscavam solução para a escolarizaçáo das crianças pequenas. As necessidades foram aumentando e tornandose mais complexas, no que se refere à escolarização das crianças e também dos jovens e adultos, à profissionalização, à formação em nível superior e, especialmente, à preocupaçáo com o conteúdo e a forma escolar, bem como com a formação de seus professores. Toma força um movimento que expressa preocupação com a educação mais ampla da base, para além da escolarização. Estas questôes levam à criação do setor de educação do MST em 1988, hoje chamado de coletivo da educação.

\section{Os desafios atuais do MST e da educação}

Os desafios do MST na atualidade não são propriamente dele, mas o são de toda a classe trabalhadora. Os movimentos sociais organizados, ainda que assumam uma multiplicidade de formas e expressóes, no nível imediato das 
lutas, tem como mote central a exploração do capital, legitimada e possibilitada pelo Estado, sobre o trabalho.

Os assentados e os sem-terra constituem uma grande massa de trabalhadores semiproletarizados, muitos dos quais vivendo nas periferias das grandes e pequenas cidades. Portanto, para além de um movimento que luta pela terra, o MST evidencia o nível e o grau de proletarizaçáo em curso dos trabalhadores brasileiros, sejam eles do campo ou da cidade. É a expressão do grande e crescente contingente de trabalhadores excedentes, de uma produção destrutiva, nos termos de Mészáros (2002), que destrói não só o meio ambiente, as mercadorias que se tornam facilmente descartáveis, mas também a força de trabalho.

Os acampamentos organizados pelo MST hoje, alguns localizados nas periferias das cidades, acolhem trabalhadores que há muito deixaram o campo e não conseguem sobreviver nas cidades. São desempregados, precarizados, favelizados junto a trabalhadores que ainda resistem para produzir sua vida no campo, de forma cada vez mais insustentável.

O que caracteriza a vida no acampamento é a organização e a luta cotidiana, numa situação de precariedade e de medo. Ainda que muitas famílias vivam durante anos acampadas, o contexto é sempre de tensão e de mudança. As escolas itinerantes expressam esta realidade, quando se organizam numa dinâmica tal qual a do acampamento, acompanhando seu movimento e experimentando formas diversas de educar/escolarizar as crianças e os jovens.

$\mathrm{O}$ assentamento é fruto da conquista dos sem-terra organizados em torno do MST. É constituído pela desapropriação de uma área, por meio do Instituto Nacional de Colonização e Reforma Agrária (INCRA). Nele, novos desafios se apresentam: o planejamento e a organização da produçáo e do trabalho, o crédito, a comercialização, a luta pela infraestrutura, de um modo geral, a moradia, a escola, a saúde, ou seja, trata-se de um recomeço na vida de famílias que perderam suas terras ou que nunca chegaram a tê-las. Alguns assentamentos são organizados de forma coletiva por meio de cooperativas, associaçóes ou outras formas cooperadas, evidenciando o que há de mais avançado na organização dos trabalhadores. Entretanto, grande parte dos assentados enfrenta dificuldades internas e externas na produção da vida.

Os assentamentos conquistados pelo MST, segundo Germer (2007), criaram uma figura artificial representada pela camada de assentados bem 
sucedidos com base em lotes individuais que se reconhecem como possuidores de terra própria e não mais como semi-assalariados, condição essa que se mantém devido à precariedade de grande parte dos assentamentos. Tal contexto tem levado o MST a focar suas lutas nas reivindicaçóes econômicas (crédito, preço, renegociação de dívidas) e técnicas (assistência, linhas de pesquisa, tecnologias alternativas).

Esse quadro tem seus reflexos no aspecto educacional, com a necessidade imediata de formação de técnicos para suprir as deficiências relacionadas especialmente à produção nos assentamentos, enfraquecendo o aspecto formativo mais amplo e os ideais de uma educação de base marxista e socialista, centrada na formação omnilateral.

Observa-se, ainda, a importância atribuída à educação, na expectativa de que ela poderá contribuir em grande medida para a formação de quadros do Movimento e para a formaçáo de técnicos para os assentamentos. Valoriza-se demasiadamente a escola, num contexto em que as promessas integradoras desta se desintegram.

A qualificação técnica de profissionais como estratégia de implementação de uma nova forma de produzir e organizar o trabalho no campo é uma proposta que pretende negar as relaçóes preconizadas pela forma capitalista de produção, construindo relaçôes mais solidárias, justas e coerentes com a perspectiva dos trabalhadores. Entretanto, tal proposta muitas vezes revela tendências utópicas e idealistas, ao delegar para a educação a solução de problemas de ordem estrutural em termos econômicos e sociais, como, por exemplo, a formação e escolarização que seja capaz de segurar as pessoas no campo, evitando o êxodo rural.

Diante das problemáticas acima apresentadas, questionamos: o que agrega os trabalhadores na atualidade? Qual é a luta capaz de unir os desenraizados de ontem e de hoje: os trabalhadores que vagueiam pelo mundo e pelo país em busca de trabalho e que já não veem mais fronteiras entre o campo e a cidade?

A condição atual do MST é também expressão do contexto nacional e internacional de lutas dos trabalhadores, por meio de movimentos sociais, sindicatos e partidos políticos de esquerda. Silver (2005, p. 34), com base em Marx, observa a transformação permanente da classe operária e da forma de conflito trabalho-capital: "a percepçâo de que o trabalho e os movimentos operários são feitos e refeitos continuamente nos fornece um antídoto importante contra a tendência comum de sermos rígidos demais ao especificarmos quem 
faz parte da classe trabalhadora". Desse modo, deve-se ficar atento para sinais emergentes de uma nova formação da classe trabalhadora, assim como de um "contra-ataque" daquelas classes trabalhadoras que estão sendo "desfeitas".

Em termos de protagonistas da ação coletiva, nosso foco é o "proletariado" (isto é, aqueles que precisam vender sua força de trabalho para sobreviver). A condição proletária abrange uma série de situaçôes concretas, desde aqueles que dispóem de habilidades escassas com muita demanda (e que portanto dispóem de um poder de barganha no mercado relativamente grande) até os desempregados. Inclui desde aqueles que trabalham para empresas privadas até os funcionários do Estado, pois estes não são menos passíveis de serem tratados como mercadorias do que, digamos os trabalhadores do mercado de trabalho interno de uma grande empresa. (SILVER, 2005, p. 47).

Para compreender o campo brasileiro e, particularmente, o MST, é preciso compreender a transformação da estrutura de classes, aspecto essencial do desenvolvimento capitalista. Germer (2004) observa no campo brasileiro a presença da burguesia (grande e média), da camada intermediária (pequena burguesia e produtor simples de mercadoria) e da força de trabalho (semiassalariado, proletariado permanente e temporário). O proletariado é o assalariado puro e o semiassalariado são os produtores semiautônomos, pois a precariedade da terra e dos recursos os obrigam a recorrer ao trabalho assalariado, fora de seu estabelecimento.

De acordo ainda com a análise de Germer (2004), na década de 1980, a burguesia desenvolveu sua estrutura de representaçáo, influenciando significativamente o Estado, por meio especialmente de duas entidades: a Frente Ampla da Agropecuária Brasileira (FAAB) e a União Democrática Ruralista (UDR), fortalecendo a organizaçáo da classe dominante agrária. Do lado dos trabalhadores, no início da década de 1980, houve um saldo positivo com o aumento do número dos sindicatos rurais combativos ligados à Central Única dos Trabalhadores (CUT) e com a consolidação do MST. Porém, no final dessa década, as entidades representativas dos trabalhadores CUT, Confederação Nacional dos Trabalhadores da Agricultura (CONTAG) e MST, apresentam divergências e não convergem para uma unificaçấo organizativa e pragmática. 
Germer (2004) identifica as bases sociais dessas entidades. O MST, onde há o predomínio do semiproletariado agrário, isto é, os pequenos agricultores cuja terra é menor de 20 hectares ou não tem terra, ou não tem equipamentos; estes sustentam uma coesão e uma combatividade. O sindicalismo, constituído de pequenos agricultores autônomos e os assalariados rurais puros, os quais não têm conseguido subordinar as lutas imediatas (econômicas) com a luta anticapitalista. $\mathrm{O}$ autor defende que é o proletariado rural que dá a direção às lutas da classe trabalhadora agrária, porque antagoniza mais com o capital. No entanto, a situação concreta atual tem demonstrado que não é o proletário rural o condutor dessas lutas, "é o semi-proletariado que assume, através do MST, a posição de luta mais contundente contra o sistema, através de sua bandeira principal, que é a reforma agrária sob o controle dos trabalhadores" (GERMER, 2004, p. 281).

No contexto político, o Brasil teve a experiência, por 8 anos, de um presidente do Partido dos Trabalhadores (PT), que conta no seu currículo com a vivência de líder sindical. Conforme análise de Dalmagro (2010), se o momento seguinte à eleição de Lula provocou ânimo e esperança entre as organizaçôes populares e de classe na perspectiva de avançarem na democratização do país e na conquista de direitos básicos, tendo em vista acumularem forças para mudanças estruturais, passados um ou dois anos de governo o que se desenhou foi um contexto político mais complexo e difícil para estes movimentos. Nos primeiros anos de governo Lula (2003, 2004 e 2005) o MST mantém em alta o número de ocupaçóes e famílias acampadas. Manter estas açóes em ritmo forte tinha como meta dar suporte ao governo para uma política mais massiva de realizaçáo da Reforma Agrária. Entretanto, isso não apenas não ocorreu como o Movimento passou a enfrentar maiores dificuldades na organização dos sem-terra. Estes, identificando que Lula não faria a tal "reforma" e cansados da demora nas desapropriaçóes de áreas passam a ter maior resistência em permanecer por longos períodos nas difíceis condiçóes do acampamento. Tal dificuldade de "massificação das ocupaçóes" também tem como importante fator as políticas assistenciais desse governo que permitem a sobrevivência dos pobres em condiçóes precárias no local onde se encontram, gerando assim uma situação de imobilização social e política.

O governo Lula ao longo de seus dois mandatos e, atualmente, o governo Dilma, não contribuíram para a democratização da terra, o fortalecimento dos movimentos sociais ou o combate à criminalização a que estão submetidas tais 
organizaçóes. Marcados pela ambiguidade em suas políticas, em face da busca de "diálogo" constante com os diferentes setores da sociedade, entretanto, a política macroeconômica e da macroeconomia agrícola não deixam dúvidas de quais forças têm mais peso no governo. Para Francisco de Oliveira (2009), o governo Lula expressou uma "hegemonia às avessas", quando os dominados fazem o discurso político conquanto que os fundamentos da dominação não sejam questionados. Oliveira (2009) aponta que se é certo que a pobreza absoluta diminuiu, não diminuiu a desigualdade social, cuja política e crescimento econômico continuaram favorecendo as classes altas.

Após alguns anos de governo do PT, é evidente que sua política em relação ao campo é de fortalecimento do chamado agronegócio, especialmente dos grandes exportadores, mas também de fortalecimento da pequena agricultura de mercado. Conforme dados do Censo Agropecuário de 2006 (IBGE, 2009), os grandes proprietários e empresas são beneficiados com $86 \%$ do crédito rural, mas são responsáveis por apenas $60 \%$ dos valores comercializados. Ainda segundo o Censo, a terra ficou mais concentrada, com o índice de GINI passando de 0,852 para 0,872 . Além do que, houve redução de $7,6 \%$ do pessoal ocupado na agricultura. No início do governo, o plantio e a comercialização de transgênicos foram liberados no país, favorecendo grandes empresas. Os dados em relação à desapropriação de áreas são bastante similares aos do governo Fernando Henrique Cardoso, mantendo a política de amenização de conflitos pontuais e não mexendo na estrutura da propriedade da terra.

Os índices em relação à violência no campo, conforme dados da Comissão Pastoral da Terra (CPT), se mantêm altos. Em 2011, houve um crescimento de $15 \%$ no número total de conflitos no campo, em relação à 2010. Estes envolvem conflitos por terra, pela água e trabalhistas. Os conflitos por terra (se referem à expulsões, despejos, destruição de bens, ameaças de pistoleiros etc.) é que apresentaram um crescimento mais expressivo, passaram de 835, em 2010, para 1.035, em 2011, um crescimento de $24 \%{ }^{4}$.

Nesse difícil e complexo contexto, quais os principais desafios para o MST? São muitos, com certeza! Compreendemos que as respostas para a situação atual de vida não podem ser construídas individualmente e nem em âmbito local. Exigem levantar bandeiras de luta que agreguem o conjunto dos trabalhadores explorados e os excedentes, que já não encontram mais trabalho e não conseguem se reproduzir como trabalhadores. Implica, ainda, superar a fronteira entre campo e cidade, vislumbrando novas formas de ocupação do 
espaço, formas sustentáveis não apenas do ponto de vista do meio ambiente, mas da vida humana. Disso decorre a necessidade de questionamento da táo propalada oposição entre agronegócio e agricultura familiar por estudiosos do campo ${ }^{5}$ inclusive pelos movimentos sociais. Será de fato esta a oposiçâo fundamental? Ao que parece, a luta centrada no fortalecimento da agricultura familiar ou camponesa, com base na produção agroecológica, em oposição ao agronegócio, desvia-se do real antagonismo de classe, enfraquece a luta mais fundamental e as possibilidades de uma coesão da classe trabalhadora.

Para Delgado (2003), o movimento camponês vem se dividindo, sob influência dos setores da pequena agricultura tecnificada que vislumbram uma associação com o agronegócio. A Igreja católica perdeu protagonismo na luta pela reforma agrária. Os partidos de esquerda, hoje no governo, administram o "ajustamento constrangido". Círculos acadêmicos e técnico-burocráticos são influenciados pelo fascínio do progresso técnico que o agronegócio domina. $\mathrm{O}$ movimento mais organizado e combativo, tendo à frente o MST, não é capaz isoladamente de organizar os amplos setores desorganizados e repelidos pelo capital financeiro na agricultura. Observa-se um processo de crescimento da violência e exclusão no meio rural e pequenas aglomeraçôes urbanas.

Em situações de crise, a tendência é buscar soluções rápidas e imediatas, perdendo de vista o projeto histórico e, portanto, os interesses de luta fundamentais para a classe trabalhadora. $\mathrm{Na}$ educação, isso é muito perceptível, ganha terreno a necessidade imediata de preparar técnicos para atender as demandas dos assentamentos, em termos de saúde, de educação e, especialmente, de produção. Consome-se energia em batalhas que poucos frutos trazem para o avanço da luta social, especialmente no campo das políticas públicas. Perde-se, muitas vezes, a perspectiva de um projeto formativo no sentido omnilateral, conforme desenvolvido por Marx.

Temos clareza de que as pessoas se movem pelas necessidades. Já afirmavam Marx e Engels (2007), em A Ideologia Alemãa que o primeiro ato histórico do homem é a produção dos meios de vida. A questão é a mediação feita pelo movimento social, sindical e pelo partido político, no sentido de passar do estágio mais inicial e imediato para o estágio mais avançado na luta de classes.

O MST nos coloca alguns desafios teóricos para estudar na atualidade o campo e a cidade, distintamente do passado quando era possível apreender o campo separadamente da cidade. E também para compreender o que é o moderno e o atrasado. Talvez o agronegócio seja o atraso e o MST represente 
o que há de mais moderno na atualidade, quando se considera como referência não o capital, mas a vida humana.

Para além dos desafios teóricos, observamos os relacionados à vida prática que se expressam na experiência coletiva, na autogestâo, na cooperação, na solidariedade presentes nas ocupaçóes, nos acampamentos e nos assentamentos organizados pelo Movimento dos Sem Terra.

Em termos educacionais, a trajetória do Movimento evidencia três elementos centrais que o mobilizam na luta por escola: a luta pela transformação social, a relação entre trabalho e educação e a formação de militantes. Estes vão ganhando contornos em meio a tensóes internas e externas e na luta entre as velhas e as novas relaçóes sociais, movem-se, portanto, em meio a contradiçóes.

\section{Notas}

${ }^{1}$ Fonte: <www.mst.org.br>. Acesso em: 30 jan. 2013.

${ }^{2} \mathrm{O}$ Censo Agropecuário 2006, divulgado pelo IBGE em 2009, mostra um agravamento da concentração de terras nos últimos 10 anos. A concentração e a desigualdade regional é comprovada pelo Índice de Gini da estrutura agrária do País, quanto mais perto esse índice está de 1, maior a concentraçáo. O Censo mostra um Gini de 0,872, reafirmando o velho quadro da concentração fundiária no Brasil. Os dados apontam que as pequenas propriedades (com menos de 10 hectares), as quais representam $47 \%$ dos estabelecimentos rurais, ocupam apenas 2,7\% da área ocupada. Já as grandes propriedades (com mais de 1000 hectares), as quais correspondem a apenas $0.91 \%$ dos estabelecimentos, ocupam $43 \%$ da área total.

${ }^{3}$ Consultar: Leonilde S. Medeiros (1989), História dos movimentos sociais no campo.

${ }^{4}$ Ver relatório completo: Conflitos no Campo (CPT) Brasil em 2011. Disponível em: <www.cptnacional.org.br>. Acesso em: 30 jan. 2013.

${ }^{5}$ Um exemplo é o geógrafo Bernardo Mançano Fernandes, um importante estudioso da questáo territorial no Brasil, especificamente no campo. 


\section{REFERÊNCIAS}

DALMAGRO, Sandra L. A escola no contexto das lutas do MST. 2010. 312 p. Tese (Doutorado em Educação) - Universidade Federal de Santa Catarina, Florianópolis, SC, 2010.

DELGADO, Guilherme C. A questão agrária no Brasil, 1950-2003. Mundo rural: Sociologias, n. 10, p. 312-347, 2003.

DELGADO, Guilherme C. Qual é a questão agrária atual? Movimento dos trabalhadores rurais sem terra, São Paulo, 16 out. 2009. Disponível em: <http://www.mst.org.br/node/8382>. Acesso em: 23 abr. 2010.

FERNANDES, Florestan. Educação e sociedade no Brasil. São Paulo: Dominius, 1966.

FERNANDES, Florestan. A revolução burguesa no Brasil: ensaio de interpretação sociológica. 5 ed. São Paulo: Globo, 2006.

GERMER, Claus. O desenvolvimento do capitalismo no campo brasileiro e a reforma agrária. In: STÉDILE, João P. (Org.). A questão agrária na década de 90. 4 ed. Porto Alegre: Editora da UFRGS, 2004.

GERMER, Claus. O sentido histórico da reforma agrária como processo de redistribuição da terra e da riqueza. Reforma Agrária, Brasília, DF, v. 34, p. 41-56, 2007

GORGEN, Sérgio A.; STÉDILE, João P. A luta pela terra no Brasil. São Paulo: Scritta, 1993.

HARVEY, David. Espaços de esperança. São Paulo: Loyola, 2005.

IBGE. Censo Agropecuário 2006: Brasil, grandes regiōes e unidades da federação. Rio de Janeiro: IBGE, 2009. Disponível em: <http://www.ibge. gov.br/home/estatistica/economia/agropecuaria/censoagro/brasil_2006/ Brasil_censoagro2006.pdf>. Acesso em: 30 jan. 2013.

LOBATO, João B. Monteiro. Urupês. In: LOBATO, João B. Monteiro. Urupês. São Paulo: Brasiliense, 1951. p. 241-256. (Obras Completas de Monteiro Lobato, série 1, v. 1).

MARX, Karl; ENGELS, Friedrich. A ideologia alemã. São Paulo: Boitempo, 2007. 
MEDEIROS, Leonilde S. História dos movimentos sociais no campo. Rio de Janeiro: FASE, 1989.

MÉSZÁROS, István. Para além do capital: rumo a uma teoria da transição. Trad. de Paulo C. Castanheira e Sérgio Lessa. São Paulo: Boitempo; Campinas, SP: Editora da UNICAMP, 2002.

MÉSZÁROS, István. O desafio e o fardo do tempo histórico. São Paulo: Boitempo, 2007.

OLIVEIRA, Francisco de. Crítica à razão dualista: o ornitorrinco. São Paulo: Boitempo, 2003.

OLIVEIRA, Francisco de. O avesso do avesso. Revista Piauí, São Paulo, n. 37, 2009.

PRADO JR., Caio. Formação do Brasil contemporâneo. São Paulo: Brasiliense, 1942.

ROMANELLI, Otaíza. História da educação no Brasil. 30 ed. Petrópolis: Vozes, 2006.

SAVIANI, Dermeval. História das idéias pedagógicas no Brasil. Campinas, SP: Autores Associados, 2008.

SILVA, José Graziano da. A modernização dolorosa. Rio de Janeiro: Zahar, 1982.

SILVER, Beverly. Forças do trabalho: movimentos de trabalhadores e globalização desde 1870. Campinas,SP: Boitempo, 2005.

SOBRAL, Francisco J. M. A formação do técnico em agropecuária no contexto da agricultura familiar no oeste catarinense. 2005. Tese (Doutorado em Educação) - Universidade Estadual de Campinas, Campinas, SP, 2005.

TOURAINE, Alain. Novos movimentos sociais. In: TOURAINE, A. Como sair do liberalismo? Tradução de Maria L. Loureiro. São Paulo: EDUC, 1999.

VENDRAMINI, Célia R. Ocupar, resistir e produzir: um estudo da proposta pedagógica do MST. 1992. Dissertação (Mestrado em Educação) Universidade Federal de São Carlos, São Carlos, SP, 1992.

VENDRAMINI, Célia R. Terra, trabalho e educação: experiências sócioeducativas em assentamentos do MST. Ijuí: Editora Unijuí, 2000.

VIANNA, Marly A. G. A preocupaçâo do movimento operário com a educação. Perspectiva, Florianópolis, SC, v. 26, n. 1, p. 253-272, jan./jun. 2008. 


\section{The challenges of the MST (Landless Workers Movement) and the education in Brazil today}

\section{Abstract}

The paper proposes a reflection on the current struggles of the Movement of Landless Workers (MST) in the context of a Brazilian reality growing urbanization. From research conducted in recent years about the educational experience of MST is shown the emergency historical context of the Movement. This is based on the linkage between the economic, political and educational aspects; in the reaction of organized landless workers, their goals and forms of struggle, and specifically, in the importance given to education, and finally in the current challenges of the MST and its educational purposes. The Movement analyzed in this paper leads us to reflect on some theoretical and practical challenges today concerning the countryside and its connection with the city, and concerning to the break of the historical concentration of land ownership and wealth in Brazil. This is connected with the struggles of organized workers and their experiences of cooperation, self-management and education / schooling of their base. Their education is understood in its historical, social, economic and political context as being the result of social relations.

Keywords: Movement of Landless Workers (MST). Educacion and social movements. Work and education.

\section{Los desafíos del Movimiento Sin Tierra y de la educación brasileña Resumen}

El presente artículo propone una reflexión sobre la actualidad de las luchas del Movimiento de los Trabajadores Rurales sin Tierra en Brasil en un contexto de creciente urbanización. A partir de las investigaciones realizadas en los últimos años sobe la experiencia educacional del MST, se presenta el contexto histórico de la génesis del Movimiento, articulando los aspectos económicos, políticos y educacionales, la reacción organizada de los trabajadores sin-tierra, sus objetivos, formas de lucha y, específicamente, la importancia atribuida a la educación, finalmente, los desafíos actuales del MST y sus propósitos educacionales. El Movimiento analizado en este texto, nos lleva a reflexionar sobra algunos desafíos teóricos y prácticos en la actualidad, referentes al campo y su articulación con la ciudad, la ruptura con la histórica concentración de la propiedad de la tierra y de la riqueza en Brasil, las luchas organizadas de los trabajadores y sus experiencias de cooperación, autogestión, y educación - escolarización de su base. La educación es comprendida en su contexto histórico, económico y social, siendo fruto de las relaciones sociales.

Palabras claves: Movimiento Sin-Tierra. Movimientos sociales y Educación. Trabajo y educación. 


\section{Célia Regina Vendramini}

E-mail: celiavendram@gmail.com

Rcebido em: 1/3/2013

Versão final recebida em: 11/5/2013

Aprovado em: 21/5/2013 